\title{
Mídia, clonagem e bioética
}

\author{
Media, cloning, and bioethics
}

Sérgi o I biapina Ferrei ra Costa 1

Débora Diniz 2

\footnotetext{
1 Centro de Ciências da Saúde, Universidade Federal do Piauí. Teresina, PI 64049-550, Brasil.

2 Núcleo de Estudose Pesqui sas em Bioética, Universi dade de Brasília. Anis: Instituto de Bioética, Direitos Humanos e Gênero. C. P. 04554 Brasília, DF 70919-970, Brasil. debdiniz@zaz.com.br
}

Abstract This article was based on an analysis of three hundred articles from mainstream Brazilian periodicals over a period of eighteen months, beginning with the announcement of the Dolly case in February 1997. There were two main objectives: to outline the moral constants in the press associated with the possi bility of cloning human beings and to identify some of the moral assumptions concerning scientific research with non-human animals that were published carel essly by the media. The authors conclude that there was a haphazard spread of fear concerning the cloning of human beings rather than an ethical debate on the issue, and that there is a serious gap between bioethical reflections and the Brazilian media.

Key words Cloning; Media; Periodicals; Bioethics; Ethics

Resumo Para este artigo, foram analisadas trezentas matérias extraídas dos princi pais jornais da mídia impressa brasileira sobre o tema da clonagem, em um período de dezoi to meses, a contar do anúncio de Dolly, feito em fevereiro de 1997. A análise do material teve dois grandes objetivos: mapear os constantes morais a que a possi bili dade da clonagem de seres humanos esteve associada eidentificar alguns dos pressupostos morais da pesqui sa científica com animais nãohumanos e que foram reproduzi dos irrefletidamente pela mídia. Além do reconhecimento de que houve antes uma difusão irrefl eti da do medo da clonagem em seres humanos que mesmo um debate éti co frente à questão, a concl usão a que os autores chegaram com este estudo foi que há um sério descompasso entre as refl exões bioéticas e a mídia brasileira.

Palavras-chave Clonagem; Mídia; Periódicos; Bioética; Ética 
Introdução

Na edição de março-abril de 1998 da revista Hastings Center Report, editada por um dos centros mais importantes do mundo na pesquisa bioética, foi publicado o artigo "Bad Copies: how popular media represent cloning as an ethical problem", de autoria de Patrick Hopkins, que, com uma perspicácia fora do comum, analisou como a mídia impressa e televisiva dos Estados Unidos lidou com a clonagem de Dolly, a ovelhinha nascida de reprodução assexuada, apresentada ao mundo em fevereiro de 1997 incialmente pela revista Nature (Hopkins, 1998). Ora, a começar pelo título "Bad Copies" ("Cópias Mal-Feitas"), uma ironia inteligente ao estilo narrativo adotado pela mídia norte-americana frente à clonagem de Dolly, o artigo de Hopkins foi antes inovador por seu argumento de fundo que mesmo por suas análises de caso. Vale acompanhar algumas das palavras iniciais do autor e que, em larga medida, resumem seu argumento-chave: “...a maioria dos americanos recebeu treinamento sobre a ética da clonagem antes de saber o que seria a clonagem propriamente dita..." (Hopkins, 1998:1). Ou seja, segundo o autor, para um grande público, aí inclusos não apenas leigos na medicina mas todos aqueles não iniciados nos segredos da genética, a ética da clonagem veio antes da técnica da clonagem.

O fenômeno Dolly na mídia, ao contrário do que se poderia deduzir da idéia de Hopkins da éti ca antes da técnica, não subverteu a lógica do pensar-fazer científico tradicional, caracterizada pelo fato de a reflexão ética, regra geral, ser posterior ao avanço científico. E, de fato, não foi neste sentido que Hopkins afirmou que, para a clonagem de Dolly, a "ética veio antes da técnica" (Hopkins, 1998:6). O que o autor considerou foi que a mídia norte-americana deteve-se antes nos aspectos morais da técnica (e, principalmente, em seus prováveis desdobramentos em seres humanos) que propriamente nas sutilezas da técnica. Pouco se falou da história da clonagem, como dos girinos e dos ratos clonados desde os anos 50 . Ou mesmo do uso da clonagem na agricultura ou na pecuária desde os anos 80 . O tempo histórico da mídia foi outro. A mídia deteve-se no futuro da clonagem. Ou melhor que isto: a mídia entreteve-se em imaginar e, muitas vezes, em fantasiar o futuro da clonagem.

Mas o futuro fantasioso não teve como protagonistas os animais clonados no tempo presente da clonagem, tais como as ovelhas (Dolly, Polly e Molly), os macacos (Neti e Ditto), os bezerros (Charlie e George) ou os ratos (estes de tão comuns à pesquisa científica são anônimos). Enquanto os animais não-humanos, já utilizados pela clonagem a título de rotina da pesquisa científica, encontram-se no passado e no presente, no futuro estaria a possibilidade de abertura da técnica para os humanos. $E$, neste futuro, infelizmente, a tônica não foi a ética da clonagem, entendida aqui em um sentido positivo da reflexão cuidadosa, mas sim a antiética da mesma. Falou-se muito mais das conseqüências negativas da técnica de que seus possíveis benefícios à humanidade. Como acertadamente escreveu o ombudsman do jornal Folha de São Paulo, em matéria do dia 2/3/97: “...A ovel ha não foi recebida com otimismo, mas antes como a prova da iminente decadência da espécie humana, incapaz de refrear seus instintos diante das mórbi das possibilidades colocadas à sua disposição pela ciência..." (Santos, 1997:1-6). Na verdade, durante os primeiros meses de divulgação da notícia, com raras exceções, quase não houve espaço na mídia para avaliar as vantagens da técnica em animais humanos.

Em certo sentido, em nome do medo e da proteção, muitas vezes irrefletida, dos animais humanos, revivemos histórias trágicas de intolerância desmedida como, por exemplo, face à astronomia na Idade Média: os biólogos escoceses incorporaram o espírito de Galileu e Dolly foi algo como a besta apocalíptica. Para utilizarmos um substantivo suave para o teor da mídia ao descrever a clonagem de Dolly, diríamos que faltou, no mínimo, tranqüilidade. A tônica foi o medo, a apreensão e a angústia moral diante de uma técnica cujas possibilidades de mal uso em humanos fizeram relembrar eventos da história mundial de que a humanidade se envergonha. Do passado histórico, resgatou-se a sombra do nazismo que obscureceu toda e qualquer possibilidade imediata de futuro digno para a clonagem em seres humanos.

Assim, diferente da tese de Hopkins sobre a divulgação da ética da clonagem como anterior à técnica, consideramos que o ocorrido, pelo anúncio de Dolly, foi antes a difusão do terror da clonagem que mesmo da ética da clonagem (para uma introdução à idéia do terror midiático frente à clonagem, vide Klotzko, 1997; Garrafa \& Diniz, 1998). Ou melhor, a antiética da clonagem veio antes da técnica ou mesmo da ética da clonagem. E neste processo de exposição das fantasias e dos possíveis malefícios da clonagem em humanos, o medo foi o grande inspirador da narrativa midiática. Fomos, portanto, primeiramente alfabetizados no medo da clonagem em humanos que mesmo apresentados à reflexão ética e crítica sobre os usos 
e abusos da técnica. O resultado foi, então, um conjunto de al egorias apocalípticas ("exército de Hitler", "fim da diversidade" ou "nascimento de Frankensteins") que transformou o hipotético defensor da clonagem em humanos num sujeito anônimo também temeroso de expor suas opiniões. Um exemplo interessante deste processo foi a matéria publicada no jornal FoIha deSão Paulo, em 2/3/97, em que numa pequena subseção do texto de página inteira sobre clonagem, intitulada "Comentário", lia-se: “...Contra o presi dente Bill Clinton, o papa eas grandes autoridades ministeriais européias, diversos médicos ouvidos por esta Folha, admitiram, 'na condição de anoni mato, é óbvio', que não vêem em princípio nenhum problema ético na duplicação de seres humanos..."[sem grifos no original ] (Schwartsman, 1997:1-6). Ou seja, sob o domínio coletivo do medo era mais do que "óbvio" que médicos simpatizantes da idéia da clonagem em humanos solicitassem o anonimato.

O medo, no entanto, foi parte considerável do explicitamente exposto pela mídia. E para a sua compreensão, o artigo de Hopkins foi fundamental. O autor enumerou os constantes morais utilizados pela mídia norte-americana por ocasião da divulgação de Dolly. Na taxonomia final, os constantes morais mais recorrentes foram agrupados em três grandes categorias, assim estipuladas pelo autor: “... perda da unicidadeeindividualidadedo humano, as motivações patológi cas de quem poderia desejar um clone e o medo da 'perda de controle' da ciência criando assim o 'admirável mundo novo"' (Hopkins, 1998:6). O mérito deste exercício analítico foi ter mapeado o universo simbólico do medo existente em torno da possibilidade de clonagem de seres humanos.

Neste artigo, repetiremos a idéia de Hopkins tendo como estudo-de-caso a mídia impressa brasileira. Usaremos a taxonomia norteamericana como pano-de-fundo para traçarmos as semel hanças e as particularidades do fenômeno Dolly na mídia brasileira. Nosso objetivo, ao analisar o estilo narrativo da mídia impressa nacional frente à Dolly, foi, contudo, além do meramente descritivo. Apontar os constantes morais comumente referidos pela mídia brasileira foi apenas o primeiro passo na identificação do que, aqui, chamaremos de pressuposto ideológico da pesquisa científica, que esteve presente em quase todas as matérias analisadas. Ou seja, utilizaremos o fenômeno Dolly como indicador de um dos dados mais importantes da pesquisa científica e que, comumente, encontra-se oculto: a ideologia especista (o conceito de especismo que utiliza- remos neste artigo é o defendido por Singer, 1993).

Antes, porém, de passarmos à apresentação de como foi feita a pesquisa, gostaríamos de esclarecer alguns de nossos pressupostos para este artigo. O primeiro é que uma análise como esta não visa pôr em julgamento a mídia propriamente dita nem tampouco a forma como noticia os fatos. Partimos da idéia de que a mídia não cria realidades, ela reproduz e redimensiona realidades que existem antes e além dela. Diferente de Arlene Klotzko que - ao analisar como a mídia norte-americana difundiu o caso Dolly em comparação à mídia inglesa julga e reprime o estilo narrativo da mídia norte-americana, considerando-a uma das principais responsáveis pela criação do terror da clonagem em seres humanos, nós, por outro lado, reconhecemos que a mídia teve (e tem) um papel fundamental na reprodução do medo e, talvez, na recriação do mesmo, mas consideramos também que o terror existe anterior e independentemente do esforço da mídia em criálo. Logo, a mídia será utilizada como o portavoz de um medo coletivo da clonagem em seres humanos. Na verdade, até mesmo entre bioeticistas famosos como é o caso de Leon Kass, bioeticista norte-americano de filiação religiosa, esta idéia irrefletida do medo face à clonagem de seres humanos é aceita. Kass a considera como parte do que chama wisdom of repugnance (sabedoria da repugnância), isto é, conhecimentos que os seres humanos possuem e não necessitam de argumentos racionais para sustentá-los (Kass, 1998). Basta apenas o apelo à sabedoria da repugnância para justificá-los, diz ele.

\section{A pesquisa}

Para este artigo, analisamos trezentas matérias jornalísticas, publicadas entre os meses de fevereiro de 1997 (anúncio de Dolly pela revista Nature) e setembro de 1998, nos seguintes jornais de circulação nacional diária: Fol ha deSão Paulo, Correio Braziliense, Gazeta Mercantil, Jornal do Brasil, O Estado de São Paulo e O Globo; além de três semanários: Época, IstoÉ e Veja. Do total de reportagens levantadas e previamente analisadas, reduzimos nossa amostra a trinta e seis matérias por consi derá-las representativas do universo selecionado e a elas faremos referências mais específicas. A alusão ao material ilustrativo que, em geral, acompanhou as matérias será feita apenas a título complementar, uma vez que suas análises foram secundárias nesta pesquisa. Registramos, 
entretanto, que uma reflexão sobre o mesmo seria de extrema valia. Além disso, antecipamos também que não foi preocupação deste artigo avaliar o grau de precisão da mídia impressa na divulgação das notíticas científicas, ou seja, consideramos que um julgamento sobre o cuidado da mídia no trato de questões científicas é outra tarefa bem distinta daquela a que nos propusemos aqui (sobre este tema da ética da comunicação científica na mídia vide, por exemplo, Jasmin, 1997; Leone, 1997 e Lucas, 1997).

"Um mundo artificial vai substituir o mundo real": as alegorias em torno da clonagem

Comecemos pelos constantes morais identificados por Hopkins em sua análise da mídia norte-americana:

1) O medo da perda da unicidade de cada ser humano.

A idéia de que a clonagem viria afetar a dignidade humana, já que acabaria com a originalidade de cada ser foi o argumento mais citado pela mídia norte-americana. O interessante desta recorrência moral, a perda da unicidade do indivíduo, é sua referência à ideologia individualista, característica marcante da sociedade norte-americana que sobrevaloriza o indivíduo e todos seus derivados filosóficos. Isto é, em um contexto de indivíduo como valor, a possibilidade de perda desta originalidade é mais grave que em outras realidades sócio-culturais. Hopkins, ao analisar um trecho da revista Time sobre o assunto, comentou com um certo ar de ironia: “...Isto conduz a um vago medo val orativo de que a clonagem é si mplesmente anti-americana...Clonagem, a revista Time teme, está ao lado dos insetos robôs e da ideologia comunista. A não-clonagem está ao lado do individualismo americano e do Mistério..." (Hopkins, 1998:9). Ou seja, a clonagem em humanos não apenas afetaria o valor-indivíduo, mas, principalmente, iria de encontro à própria idéia de construção de nação para os norte-americanos. A possibilidade de clonagem de humanos incorporou, em alguma medida, a simbologia do inimigo.

2) O recei o do surgimento de projetos megalomaníacos por parte de indi víduos egocêntricos.

Esta idéia foi a que maior referência fez a filmes e à literatura de ficção científica, como por exemplo ao filme The Boys from Brazil (Os Meninos do Brasil), ao livro Brave New World de Aldous Huxley (Admirável Mundo Novo) e à ideo- logia do estado nazista, especialmente à figura de Hitler. Entre os projetos megalomaníacos passíveis de serem realizados por intermédio da clonagem, estariam os milionários que desejariam se replicar ou os grandes investidores repletos de inimigos em busca de sócios confiáveis ou mesmo modelos ou cantores famosos (Sharon Stone e Michael Jackson encabeçaram a lista dos clonáveis pela mídia norte-americana).

3) O desejo de substituição de uma criança morta.

Este projeto moral apontado como possível por intermédio da clonagem foi o que maior simpatia teve dos americanos comuns, os americanos classe-média, como chamou o autor: “...Comumente contrastada aos projetos megaIomaníacos ou egoístas, a motivação do casal por clonar, visando "substi tui r" a criança morta, éa quetem a maior simpatia da classe- mé dia" (Hopkins, 1998:10). A substituição do fiIho-querido-morto foi um dos poucos projetos de clonagem humana moral mente aceitáveis juntamente à idéia de produção de órgãos para transplantes ou de utilização da clonagem como técnica reprodutiva para casais radicalmente inférteis.

Se por um lado estas três grandes categorias foram as que maior recorrência apresentaram na mídia dos Estados Unidos, a mídia impressa brasileira, por outro lado, desenhou duas grandes tendências. Antes de apresentálas, vale lembrar que não é necessário recorrer às teorias da comunicação social para sabermos que boa parte do que se divulga sobre temas científicos internacionais na mídia brasileira é reinterpretação do já publicado em outros periódicos ou mesmo cópias mal-feitas do já divulgado (houve, é claro, algumas exceções a estas cópias mal-feitas, publicadas na sua maioria pela mídia especializada em divulgação científica; por exemplo Dieguez, 1997: Como Foi Possível?; Schramm, 1997: O Fantasma da Clonagem Humana e Garrafa \& Diniz, 1998: Clonagem, Terror e Mídia). Ou seja, em alguma medida os constantes morais identificados por Hopkins em sua análise da mídia norte-americana também podem ser encontrados nas matérias sobre clonagem extraídas da mídia brasileira; porém, o mais interessante para nós vem sendo o reconhecimento de constantes morais nacionais, se assim podemos denominar as peculiaridades da angústia moral provocada pela clonagem no contexto brasileiro. Vamos, então, aos constantes morais encontrados na mídia brasileira:

1) A mais importante delas éa referência à Igreja Católica e aos seus postulados morais contrários à cl onagem de seres humanos. 
Em matéria publicada no Estado de São Paulo, poucos dias após o anúncio de Dolly, 27/2/97 (Vlahou, 1997), lia-se a seguinte manchete: “Vaticano pede proibição de clonagem humana", sendo seguida de uma enorme fotografia do papa em movimento de bênção. O texto da matéria, em entrevista a um bioeticista italiano, de inspiração religiosa, dizia: “...A possibilidade declonar uma pessoa traz à mente o terrível caso do nazista Menguel e... esta seria a forma mais forte dedomínio do homem sobreo homem..." (Vlahou, 1997). A referência ao Evangelium Vitae, principal documento que suporta os argumentos religiosos contrários à manipulação da reprodução humana, teve por objetivo reforçar a autoridade de Deus na criação da vida e, ao mesmo tempo, visou destituir o ser humano de seu projeto cosmogônico de recontar a origem da vida. A metáfora mais recorrente foi a que, assim como os físicos conheceram o pecado com a construção da bomba atômica, os cientistas de Dolly intentaram conhecer a criação, um projeto vedado aos humanos. Em uma matéria publicada no Correio Braziliense (1997b), no dia 2/3/ 97, intitulada "Reli giões, inquietas, pedem cautela", onde a foto do papa ocupava quase a metade da página do jornal, lia-se logo nas primeiras linhas: “...A vida ainda é uma exclusividade de Deus...". Além desse recurso à autoridade da I greja Católica como fonte normatizadora da prática, o uso da linguagem religiosa para descrever a descoberta foi uma constante. Manchetes com forte teor apelativo como as que se seguem foram muito comuns: "Homem brinca de ser Deus" (Correio Braziliense, 1997a), "Os erros dos sócios de Deus" (O Estado de São Paulo, 1997), “O homem quequer ser Deus" (Gomes, 1998).

2) A referência a projetos megalomaníacos.

Assim como o encontrado por Hopkins, também identificamos uma referência constante à possibilidade da clonagem reproduzir indivíduos que se julgam melhores que outros. Diferente, no entanto, do desenvolvido pela mídia norte-americana em que os clonáveis seriam Sharon Stone ou Ronald Reagan, para a nossa realidade, os al vos dos projetos egóicos estariam fora do Brasil e não entre nós. Sofreríamos as conseqüências do ego de um louco clonado. Se clonados, não o seríamos para liderar, mas sim para sermos escravizados, seríamos o exército dos manipulados. Assim, enquanto nos Estados Unidos a pergunta foi “quem será clonado?", entre nós a certeza foi de que, com raríssimas exceções de clonáveis como Pelé ou Ronaldinho com o intuito de formarmos um time de futebol perfeito (vide, por exemplo, a foto da matéria da revista Veja, em
5/3/97 (Alcântara, 1997), que anunciou Dolly, onde se vê um time de futebol composto apenas por Ronal dinhos), não seríamos os clonáveis, uma vez que para os padrões hierárquicos mundiais os nossos humanos seriam menos humanos. Outra possibilidade, em que brasileiros clonáveis foram cotados, mas em tom de humor, teve a dançarina Carla Perez como uma das mais votadas, em pesquisa realizada pelo jornal Fol ha deSão Paulo, em 1/3/ 97 (Gutkoski, 1997). Se alguém pensar em clonar brasileiros, dizia ainda o jornalista, é para servir a interesses escusos, como o sugerido pelo filme Meninos do Brasil.

3) A possi bilidade da reprodução sem o macho.

Não temos como afirmar se este tópico não esteve presente nos artigos da mídia norteamericana ou se não foi recorrente a ponto de o autor catalogá-lo. Curiosamente, entre nós, encontramos uma série de artigos que apontavam para o possível descarte do macho no processo reprodutivo com o advento da clonagem como técnica reprodutiva. Para uma jornalista, se, um dia, houver a difusão e popularização da clonagem, os homens correrão perigo. Poderemos ter, dizia outra jornalista mais afoita, uma sociedade de mulheres. Um psicanalista, irônica e debochadamente, proclamou a era da clonagem como "o fim da era do espermatozói de"; dizia ele em uma matéria publicada na Gazeta Mercantil em 28/2/97: “...Prevê-se agora uma nova avalanche cultural de feministas leves e pesadas - de Gloria Stei nem a Camille Paglia. Dolly significa nada menos que o fim da era do espermatozói de..." (Escobar, 1997). Dolly, dizia ele, foi a primeira fêmea a ter nascido de três mães e nenhum pai. Em outra matéria, datada no dia 16/3/97, no jornal Fol ha de São Paulo (Lara, 1997), lia-se: “...Não há dúvida de que um avanço tecnológico enorme foi alcançado. Ele não dispensa, contudo, o uso deóvulos. Eles são importantíssi mos para o processo...Nesse caso, o queficou dispensado foi o macho!...".

Além dos constantes morais enumerados acima, outras possibilidades de mal uso da técnica da clonagem em humanos foram sugeridas. A idéia de fabricação de seres metamorfoseados - os monstros da criação humana, em que a figura de Frankenstein estaria para os humanos assim como o Rama, um animal engenherado misto de camelo e Ihama, para os animais não-humanos - foi comum, até mesmo pelas suas referências à engenharia genética como a ciência da manipulação da vi$\mathrm{da}$, fato que, na verdade, é anterior à clonagem propriamente dita. O curioso, no entanto, é que, se, por um lado, a idéia da fabricação de 
seres-Frankensteins ou, ainda, de humanos com características genéticas pré-selecionadas, foi recebida com profundo desprezo e, até mesmo, foi rejeitada pela mídia brasileira, a criação de animais não-humanos sem precedentes na natureza, como o Rama, foi, por outro lado, considerada um grande avanço científico. Vale conferir trechos da reportagemanúncio do Rama na Veja (1998), em 28/ 1/ 98 : “...Para que foi criado um animal assim? 'Esperamos que elevenha a ter as melhores qualidades de cada uma das duas espécies', afirma Skidmore, uma especial ista em reprodução de camelo...Ela acredita que o Rama vai produzir lã nobre como a do Ihama, mas em quantidade maior por causa do tamanho...O experimento foi possível porque camelo el hama descendem de um mesmo ancestral que viveu há $30 \mathrm{mi}$ Ihões de anos..."[sem grifos no original ]. Ora, algumas das expressões utilizadas pela pesquisadora, especialmente as grifadas, apontam para as conseqüências da ideologia especista na prática científica, as quais conduzem o pesquisador a lidar com a técnica sob perspectivas radical mente diversas a depender do sujeito da pesquisa, se humanos ou animais não-humanos.

\section{"Monstros de mil utilidades": a ideologia especista e a clonagem dos animais não-humanos}

Uma análise direcionada às manchetes do fenômeno Dolly seria o material etnográfico suficiente para refletir sobre a ideologia especista do pensar-fazer científico. Na verdade, as conseqüências do olhar especista foram tão ou mais marcantes que as provocadas pelo medo frente à clonagem. Por um lado, poderíamos até mesmo considerar que os efeitos da ideologia especista sob a mídia foram ainda mais perniciosos que os provocados pelo terror da possibilidade da clonagem em seres humanos. Como já foi mencionado, após um ano da divulgação de Dolly, iniciou-se um pequeno movimento por parte da mídia nacional com o intuito de revisitar a aversão desmedida frente à clonagem (um exemplo foi "Relatório vê vantagens em clonar humanos", publicado na Fol ha de São Paulo, em 13/ 1/ 98 - Laurance, 1998). Foram matérias isoladas, é claro, mas o mesmo não se processou diante dos princípios da ideologia especista. A ideologia especista permaneceu no lugar silencioso do não-dito e, o mais importante, manteve-se inabalável. Seu uso foi absolutamente irrefletido, seja por parte dos cientistas ou dos leigos.
O conceito de especismo foi originalmente difundido na bioética por Peter Singer, no livro Animal Liberation, para quem a ideologia especista seria uma forma de "...tirania dos humanos sobre os animais não-humanos..." (Singer, 1990:i). Após este livro, o autor publicou outros escritos sobre a questão, mas foi em Ética Prática - a obra que o tornou mundialmente conhecido - onde Singer retomou algumas das idéias originais contidas em Animal Liberation, reforçando ainda mais suas comparações com os humanos, especialmente com o que denominou os humanos não-pessoas (Singer, 1993). Assim, o autor definiu o especismo: “...Especismo - a palavra não éatraente, masna ausência de outra melhor - é o preconcei to ou uma atitude sel etiva em favor dos interesses dos membros da própria espécie em detrimento dos membros de outras espécies..." (Singer, 1990:6). A etimologia do conceito remete, portanto, a outras práticas discriminatórias já conhecidas do pensamento coletivo, tais como o racismo ou o sexismo. O autor considera que, assim como o racismo que se fundamenta no pressuposto da superioridade de algumas raças em detrimento de outras ou o sexismo que se baseia na hierarquia de um sexo sobre o outro, o especismo parte, por um lado, de uma supremacia dos humanos em face de outros animais e, por outro lado, de um certo desprezo pelos animais não-humanos. O especismo é, então, em larga medida, um recurso ideológico que visa proteger os membros da espécie Homo sapiens quando em conflito com os interesses de outros animais não-humanos.

Todo esse aparato teórico-ideológico esteve presente no teor narrativo do fenômeno Dolly pela mídia impressa brasileira, especialmente nas diferenças narrativas entre humanos e animais não-humanos. Vale conferir as palavras de um jornalista da revista Veja, em 14/ 1/98, por ocasião do anúncio do cientista Richard Seed de que iria clonar seres humanos (a manchete era "O homem que quer ser Deus"): “...Seed abriu uma das portas da mais perturbadora ciência moderna, um limiar que até agora nenhum outro cientista ousara cruzar..." (Gomes, 1998:42). Ora, enquanto a técnica da clonagem esteve restrita aos animais não-humanos e às plantas não houve nenhum estardalhaço nacional, nem mesmo mundial, sobre a produção de vida por reprodução assexuada ou fruto de manipulação laboratorial. Até aí, nenhum cientista que criasse vidas em um balde (como dizia um jornalista - Morais, 1997 - , em artigo no Estado de São Paulo, 28/2/97, sobre a desova dos salmões: “...tudo isso ocorre num balde, desses de plástico...") ou que repro- 
duzisse características genéticas de um animal não-humano em outro (como os frangos que foram programados para cantar como codornas) foi considerado "sócio deDeus" ou mesmo foi visto como tendo pretensões divinas. $\mathrm{Na}$ verdade, o pecado da manipulação, ou melhor dizendo, os limites éticos face à mani pulação genética, somente começaram a ser discutidos quando a ciência ameaçou tocar em uma de suas mais sagradas criaturas: os seres humanos.

A questão não esteve, portanto, na técnica da clonagem propriamente dita ou em seus benefícios para os humanos por meio dos animais não-humanos, mas na possibilidade de manipulação direta de humanos. Ou segundo palavras dos jornalistas: “...Diante do Instituto Roslin, pergunta-se ao futuro: o queacontecerá nestes laboratóri os? Os mais temerosos imagi nam que uma nova maldição pode nascer dali, um dia: a possibilidade de clonar seres humanos... (Sá, 1997)”, “...A invenção de Dolly abre de fato a possibilidadedeclonagem de seres humanos...” (Sá, 1997), “...mas as principai s questões levantadas pelo artigo deWilmut dizem respeito à possi bi li dade de cl onagem humana..." (Sá, 1997), somente para citarmos al guns exemplos. Logo, não é vedado aos humanos brincarem de Deus; eles devem, apenas, selecionar bem seus brinquedos. Todos os animais não-humanos estão, à princípio, disponíveis, as ressal vas remetem a casos específicos como a extinção ou ao número de animais utilizados em cada procedimento, como considerou, por exemplo, o porta-voz oficial de bioética da Igreja Católica: “...é diferente a posição da Igreja [Católica] com relação à clonagem de animais. Segundo o monsenhor [diretor do Instituto Catól ico deBioé tica], é acei tável, mas apenas se for praticada em número restrito deanimais e não colocar em perigo a espécie..." (Vlahou, 1997:A16).

Deixemos de lado a pergunta se os seres humanos valem ou não este respeito que justifique uma não-manipulação em seu nome. Esse seria tema para outro artigo. E assim como Singer que considerou “...o objetivo do meu argumento éelevar o status dos animais, enão diminuir o dos seres humanos..." (Singer, 1993: 88), nossa intenção não é avaliar se os humanos são ou não dignos de tamanha deferência, o que buscamos, na verdade, é apontar algumas das conseqüências deste protecionismo irrefletido. E, para isto, o fenômeno Dolly fornece pistas singulares. Foram produzidos cerca de 277 embriões antes do anúncio definitivo de Dolly (Wilmut et al., 1997). Segundo consta, foram ovel has mal-formadas, seres dignos do adjetivo "monstro" tão comumente utilizado pelos jornalistas que escreveram sobre o assunto.
Ora, as centenas de ovelhas-monstro foram um fato, antes mesmo que a possibilidade de criação de humanos-monstro. E, para este fato, do total de artigos analisados, não encontramos uma matéria sequer que se pronunciasse contrariamente. Não nos deparamos com nenhuma entidade de defesa ou de proteção da vida de animais não-humanos denunciando os abusos da técnica. Do ponto de vista ético ou antiético, falou-se apenas da possibilidade do uso da técnica em humanos. E sobre isto, todos os "advogados" da espécie humana se pronunciaram: teólogos, bioeticistas (estes em pequeno número), cientistas, juristas, antropólogos, psicanalistas, filósofos, etc. Todos, quando convidados a falar, reproduziram não apenas a ideologia especista, mas também, e principalmente, o princípio da santidade da espécie humana em detrimento de outros animais nãohumanos (sobre o princípio da santidade da vida humana vide Kuhse, 1987). Eles repetiram, quase que em coro, o princípio da intocabilidade da vida humana.

A questão da clonagem de Dolly fechou-se, portanto, em torno de três pontos fundamentais: o medo, a ideologia especista da ciência e o princípio da santidade da vida dos membros da espécie humana. Assim, refletir sobre as possibilidades de benefício da técnica ou mesmo de seus usos em humanos somente poderão ocorrer, caso se reflita antes sobre esta tríade moral arraigada ao pensamento científico.

Para além do medo... A principal lição de Dolly na mídia

No Brasil, a relação entre a mídia e a bioética, apesar de urgente, inexiste. Os bioeticistas ainda não ocuparam o espaço midiático e os poucos convidados a se pronunciar sobre o fenômeno Dolly, por exemplo, o fizeram antes como representantes de entidades dogmáticas que mesmo como bioeticistas acadêmicos ou estudiosos da ética da clonagem. Dentre o total de matérias analisadas, os poucos bioeticistas brasileiros que encontramos com voz ativa sobre a questão se confundiram, na maioria das vezes, com postulados confessionais, em geral os da Igreja Católica. Afora isto, quando houve referências à bioética laica, estas se deram de maneira tangencial e, em geral, buscou-se o recurso de autoridade fora do Brasil, como, por exemplo, nos comitês consultivos de bi oética de outros países ou mesmo em trechos de entrevista a bioeticistas estrangeiros reproduzidos já de outras matérias. Infelizmente, o poder esclarecedor e desmistificador da bioéti- 
ca ficou fora da descrição que a mídia brasileira fez do fenômeno Dolly. E, sem sombra de dúvida, este descompasso entre a bioética laica e a mídia foi também um dos grandes responsáveis pela difusão irresponsável do medo diante da possi bilidade de clonagem dos seres humanos.

\section{Referências}

ALCÂNTARA, E., 1997. Dolly, a revolução dos clones. São Paulo: Veja, 5 mar. pp. 92-99.

CORREIO BRAZILIENSE, 1997a. Homem brinca de ser Deus. Brasília: Correio Braziliense, 2 mar. Mundo, pp. 3-4.

CORREIO BRAZILIENSE, 1997b. Religiões, inquietas, pedem cautela. Brasília: Correio Braziliense, 2 mar. Mundo, p. 10.

DIEGUEZ, F., 1997. Como foi possível? São Paulo: Super Interessante, abril, pp. 38-43.

ESCOBAR, P., 1997. Clonagem deixa Europa alarmada. São Paulo: Gazeta Mercantil, 28 fev. Internacional. p. A22.

GARRAFA, V. \& DINIZ, D., 1998. Clonagem, terror e mídia. São Paulo: Jornal do CREMESP, Ano XVII, no 127 , março, s/pp.

GOMES, L., 1998. O homem que quer ser Deus. São Paulo: Veja, 14 jan. 1998, pp. 42-44.

GUTKOSKI, C., 1997. Carla Perez éa mais “clonável”. São Paulo: Folha deSão Paulo, 1 de mar. Ciência, p. 12

HOPKINS, P. D., 1998. Bad copies: How popular media represent cloning as an ethical problem. Hastings Center Report, 28:6-13.

JASMIN, C., 1997. Science, médecine, société et médias. Journal International de Bioéthique, 8:39-46.

JOBIM, N. F., 1997. Clonagem provoca polêmica. Rio de Janeiro: Jornal do Brasil, 11 mar. Saúde, p. 6.

KASS, L. R., 1998. The wisdom of repugnance. In: The Ethics of Human Cloning (L. R. Kass \& J. Q. Wilson, eds.), pp. 3-60, Washington: American Enterprise Institute Press.

KLOTZKO, A. J., 1997. The debate about Dolly. Bioethics, 11:427-438.

KUHSE, H., 1987. The Sanctity-of-Life Doctrine in Medicine: A Critique. Oxford: Clarendon Press.

LARA, F. J. S., 1997. O sapo veio antes da ovelha. São Paulo: Fol ha deSão Paulo, 16 mar. Mais!, p. 7.

LAURANCE, J., 1998. Relatório vê vantagens em clonar humano. São Paulo: Fol ha deSão Paulo, 13 jan. Ciência, pp. 1-11.
LEONE, S., 1997. Ethique de la communication médicale. Journal International de Bioéthique, 8:23-37.

LUCAS, P., 1997. L'information scientifique: Un débat sans sujet. Journal International de Bioéthique, 8 : 15-21.

MORAIS, J. C. C., 1997. Dolly e a sociedade moderna. São Paulo: O Estado de São Paulo, 28 fev. Genética, p. A2.

O ESTADO DE SÃO PAULO, 1997. Os erros dos sócios de Deus. São Paulo: O Estado deSão Paulo, 17 mar. Ciência, p. A3.

O GLOBO, 1997. Carne de animais clonados será comum no futuro. Rio de Janeiro: O Globo, 8 mar. Ciência eVida, p. 36

SÁ, V., 1997. Monstros de Mil Utilidades. Folha deSão Paulo. São Paulo, 16 mar. Caderno Mais!, 5-6.

SCHWARTSM AN, H., 1997. Além da ética e da repugnância. São Paulo: Folha de São Paulo, 2 mar. Mundo, pp. 1-22.

SANTOS, M. V., 1997. Clonar ou não clonar, eis a questão? São Paulo: Fol ha de São Paulo, 2 mar. Ombudsman, pp. 1-6.

SCHRAM M, F. R., 1997. O fantasma da clonagem humana. Ciência Hoje, 127:35-42.

SINGER, P., 1990. Animal Liberation. New York: Avon Books.

SINGER, P., 1993. Ética Prática. São Paulo: Martins Fontes.

VEJA, 1998. Farmácias vivas. São Paulo: Veja, 28 jan. p. 40.

VLAHOU, A., 1997. Vaticano pede proibição de clonagem humana. São Paulo: O Estado de São Paulo, 27 fev. Genética, p. A-16.

WILMUT, I.; SCHNIEKE, A. E.; MCWHIR, J.; KIND, A. J. \& CAM PBELL, K. H. S., 1997. Viable offspring derived from fetal and adult mammalian cells. Nature, 385:810-813. 